\title{
EDUCANDO OS HOMENS DE “MÃOS DESARMADAS”: A ABCAR COMO APARELHO IDEOLÓGICO DO ESTADO
}

\author{
EDUCAR A LOS HOMBRES COM “MANOS DESARMADAS”: LA ABCAR COMO \\ APARATO IDEOLÓGICO DEL ESTADO
}

\section{EDUCATING MEN WITH "UNARMED HANDS": THE ABCAR AS THE IDEOLOGICAL} APPARATUS OF THE STATE

DOI: http://dx.doi.org/10.9771/gmed.v12i3.34462

\section{Wallace Lucas Magalhães ${ }^{1}$}

Resumo: Qual o papel da extensão rural no Brasil e as decorrências de sua nacionalização pelo governo brasileiro na década de 1950? Quais os grupos e interesses ligados a este processo? De forma a responder tais indagações, o presente artigo tem como objetivo analisar a atuação da Associação Brasileira de Crédito e Assistência Rural (ABCAR) como aparelho de ideologia na construção do consenso quanto ao modelo de modernização agrária a partir da década de 1950. Partindo do referencial teórico de Nicos Poulantzas e suas reflexões sobre o Estado capitalista, buscou-se demonstrar o importante papel da associação na construção e consolidação dos interesses dos grupos dominantes ligados ao campo, destacando-se nesse processo o papel da ideologia.

Palavras-chave: Estado, ideologia, ABCAR.

Resumen: Cuál es El papel de La extensión rural em Brasil y las consecuencias de sua nacionalización por parte del gobierno brasileño em la década de 1950? Qué grupos e intereses están vinculados a este proceso? Para responder a estas perguntas, este artículo tiene como objetivo analizar el desempeño de la Asociación Brasileña de Crédito y Crédito y Asistencia Rural (ABCAR) como um aparato ideológico em la construcción Del consenso sobre el modelo de modernzación agrária de la década de 1950. El marco teórico de Nicos Poulantzas y sus reflexiones sobre El estado capitalista buscaban demostrar El importante papel de la asociación em la construcción y consolidación de los intereses de los grupos dominantes vinculados AL campo, destacando em este proceso El papel de la ideologia.

Palabras clave: Estado, ideologia, ABCAR.

Abstract: What is the role of rural extension in Brazil and the consequences of its nationalization by the Brazilian government in the 1950s? What are the groups and interests linked to this process? In order to answer these questions, this article aims to analyze the performance of the Brazilian Association of Rural Credit and Assistance (ABCAR) as an ideological device in building consensus on the model of agrarian modernization from the 1950s. Based on the theoretical framework of Nicos Poulantzas and his reflections on the capitalist state, we sought to demonstrate the important role of the association in the construction and consolidation of the interests of dominant groups linked to the countryside, highlighting in this process the role of ideology.

Keywords: State, ideology, ABCAR.

\section{Introdução}

Grande expoente da teoria marxista sobre o Estado, Nicos Poulantzas nos oferece um importante instrumental para se compreender como se dá a dominação de uma classe sobre as demais no modo de produção capitalista. Para se entender esse processo, fundamental é a sua abordagem acerca do Estado e sua instrumentalidade como referencial teórico. Para o entendimento dessa questão, nos 
debruçamos sobre e reflexão que identifica no Estado (nos diversos modos de produção) a sua função de manutenção da coesão de uma formação social, mantendo seu equilíbrio a partir do conjunto de dimensões da vida social, o econômico, o político, o ideológico.

A função organizativa do Estado foi bem abordada por Friedrich Engels, uma das referências de Poulantzas quanto à função estatal de coesão de uma formação social.

Vejamos a passagem de Engels sobre a função do Estado:

O Estado não é pois, de modo algum, um poder que se impôs à sociedade de fora para dentro; tampouco é "a realidade da idéia moral", nem "a imagem e a realidade da razão", como afirma Hegel. É antes um produto da sociedade, quando esta chega a um determinado grau de desenvolvimento; é a confissão de que essa sociedade se enredou numa irremediável contradição com ela própria e está dividida por antagonismos irreconciliáveis que não consegue conjurar. Mas para que esses antagonismos, essas classes com interesses econômicos colidentes não se devorem e não consumam a sociedade numa luta estéril, faz-se necessário um poder colocado aparentemente por cima da sociedade, chamado a amortecer o choque e a mantê-lo dentro dos limites da "ordem". Este poder, nascido da sociedade, mas posto acima dela se distanciando cada vez mais, é o Estado (...) Como o Estado nasceu da necessidade de conter o antagonismo das classes, e como, ao mesmo tempo, nasceu em meio ao conflito delas, é, por regra geral, o Estado da classe mais poderosa, da classe economicamente dominante, classe que, por intermédio dele, se converte também em classe politicamente dominante e adquire novos meios para a repressão e exploração da classe oprimida (ENGELS, 1984. p.191-193)

A partir dessa premissa, Poulantzas desenvolve a idéia de coesão como papel do Estado a partir da totalidade das práticas sociais, destacando que "este equilíbrio jamais é realizado enquanto tal pelo econômico, antes é mantido pelo Estado" (POULANTZAS, 1977. p.43), enquanto agente sobre uma formação social, sendo esta uma unidade complexa de instâncias (econômico, político e ideológico), afirmando que o "papel global do Estado como fator de coesão de uma formação social pode enquanto tal diferenciar-se em modalidades particulares com respeito aos diversos níveis de formação, quer dizer em funções econômica, ideológica e política no sentido estrito do termo” (POULANTZAS, 1977. p.51).

Embora à análise das diversas instâncias sociais possam ser atribuídos importantes objetos de reflexão, Poulantzas expõe como central a função global de organização do Estado, destacando que a compreensão dessas “diversas funções particulares do Estado, mesmo as que não concernem diretamente ao nível político em sentido estrito - o conflito de classes -, não podem ser teoricamente apreendidas. senão na sua relação, quer dizer, inseridas no papel político global do Estado” (POULANTZAS, 1977. p.51).

Inserido no modo de produção capitalista, Poulantzas define o Estado da seguinte forma:

O traço distintivo fundamental, a este respeito, parece consistir, com efeito, no fato de estar ausente a determinação de sujeitos (fixados, neste Estado, como "indivíduos", "cidadãos", "pessoas políticas") enquanto agentes da produção, o que não acontecia com os outros tipos de Estados. Este Estado de classe apresenta de específico o fato da dominação política de classe estar constantemente ausente das instituições. Este Estado apresenta-se como um Estado-popular-de-classe. As suas instituições estão organizadas em torno dos princípios da liberdade e da igualdade dos "indivíduos" ou "pessoas políticas". A legitimidade deste Estado está agora baseada, não na vontade divina implicada no princípio monárquico, mas no conjunto dos indivíduos-cidadãos formalmente livres $e$ iguais, na soberania popular e na responsabilidade laica do Estado para com o povo. O próprio "povo" é erigido em princípio de determinação do Estado, não enquanto composto por agentes da produção distribuídos em classes sociais, mas enquanto massa 
de indivíduos-cidadãos, cujo modo de participação em uma comunidade política nacional se manifesta no sufrágio universal, expressão da "vontade geral". O sistema jurídico moderno, distinto da regulamentação feudal baseada nos privilégios, reveste um caráter "normativo", expresso em um conjunto de leis sistematizadas a partir dos princípios de liberdade e igualdade: é o reino da "lei". A igualdade e a liberdade dos indivíduos-cidadãos residem na sua relação com as leis abstratas e formais, as quais são tidas como enunciando essa vontade geral no interior de um "Estado de direito". O Estado capitalista moderno apresenta-se, assim, como encarnando o interesse geral de toda sociedade como substancializando a vontade desse "corpo político" que seria a "nação" (POULANTZAS, 1977. p.119).

O que se extrai dessa definição, além dos efeitos das estruturas (o jurídico-político) sobre os diversos agentes da sociedade, é a função da ideologia, entendida como a ideologia dominante na consolidação da coesão social.

É a partir da função ideológica do Estado, ou de seus aparelhos e instituições, que podemos destacar a dimensão apolitica e abistórica da atuação da Associação Brasileira de Crédito e Assistência Rural (ABCAR) junto às populações rurais. Suas ações abordavam como mecanismo de progresso dessas populações o rompimento com o atraso em que viviam mediante a introdução de práticas modernas, ocultando aspectos estruturais da desigualdade no campo, como o latifúndio, por exemplo.

\section{A nacionalização da extensão rural no Brasil: a criação da ABCAR e sua função ideológica}

A maximização da produtividade do setor agrícola, embora presente nos projetos políticos nacionais após o fim da Segunda Guerra Mundial, ganhou em 1956 uma dinâmica mais intensa com o plano de metas de Juscelino Kubitschek, compromissado com a aceleração do desenvolvimento econômico capitalista. O "nacional-desenvolvimentismo" de JK se articulava a outro projeto, responsável pela estabilidade política de seu governo: o projeto ruralista. Moreira (2003) destaca este projeto não como adverso à industrialização projetada por $\mathrm{JK}$, mas como um pacto de interesses convergentes. A integração entre os espaços rural e industrial foi um dos mecanismos mais efetivos do desenvolvimento ligado ao plano de metas de JK, conectando os setores industrializados aos agroexportadores. Esse processo favoreceu o fortalecimento de um mercado consumidor de produtos industriais nas áreas localizadas fora dos eixos urbanos, concomitantemente à expansão do mercado interno de produtos agrícolas face à urbanização e à produção de matérias-primas para a indústria. A industrialização consolidada durante o governo JK foi fortalecida pela diversificação dos interesses da classe ruralista, elemento fundamental no contexto político nacional, apoiando-se mutuamente. Nesse sentido, destaca a historiadora a apropriação do projeto desenvolvimentista de JK pela classe ruralista, argumentando que:

Gostassem ou não da industrialização, das massas proletárias, do crescimento das cidades, da imprensa atuante, dos movimentos sociais e da democratização, tudo isso já era fato concreto. Em lugar de lutarem contra a maré, procuraram influir, disciplinar e aproveitar as oportunidades abertas pelo próprio processo em andamento. Buscaram, sobretudo, construir um novo pacto político para orientar o processo de desenvolvimento brasileiro, capaz de articular e harmonizar seus objetivos e reivindicações com os novos e grandes interesses industriais (MOREIRA, 2003. p.178179) 
No cenário em que os interesses "tradicionais" e "arcaicos" da classe ruralista, como o latifúndio e o poder dele decorrente, entrelaçavam-se a aspectos da modernização e do desenvolvimento, que JK assinou, em 21 de junho de 1956, o contrato para criação da Associação Brasileira de Assistência e Crédito Rural (ABCAR). A ABCAR veio a consolidar um sistema nacional de extensão rural, cujo modelo era a Associação de Crédito e Assistência Rural de Minas Gerais (ACAR-MG)2 fortalecendo o sistema extensionista como política de Estado. A criação da ABCAR representou a manutenção e estabilidade dos métodos extensionistas, além de, através da nacionalização do programa, fomentar o surgimento de outras associações a nível estadual.

Institucionalizado em 1956 como um projeto nacional, deve-se buscar, a partir do modelo implementado em Minas Gerais, alguns importantes mecanismos de integração do projeto extensionista a nível nacional, destacando-se o acordo firmado em 26 de junho de 1953 entre Brasil e Estados Unidos para a execução de um programa de cooperação agrícola (UNITED STATES OF AMERICA, 1953).

Para a organização, administração e execução do programa, previa ainda o acordo a criação de um escritório, denominado Escritório Técnico da Agricultura (ETA), sob direção conjunta dos dois governos, cujos projetos empreendidos pelo acordo e executados pelo escritório poderiam abranger a cooperação com órgãos governamentais, federais, estaduais e municipais brasileiros, bem como organizações de caráter público ou privado e com organizações internacionais de que Brasil e Estados Unidos fossem membros (UNITED STATES OF AMERICA, 1953).

A atuação do escritório ganhou destaque nos Relatórios do Ministério da Agricultura, publicação oficial que externava as atividades do órgão. Dentre seus diversos assuntos, a cooperação agrícola entre Brasil e Estados Unidos via atuação do ETA ganhou grande relevância, tendo na educação um importante elemento de captação das comunidades rurais.

Ao enfatizar as atividades do Ministério da Agricultura entre os anos de 1954 e 1955, o Relatório deu ênfase à atuação do ETA, que:

Dedicando especial interesse ao desenvolvimento do ensino profissional para as atividades rurais - agronomia e veterinária associadas á experimentação e com prática de extensão, economia doméstica, mecanização - o ETA não somente tem estimulado várias iniciativas nesses setores, como realiza um estudo objetivo das condições vigentes naquele ensino, sob todos os aspectos, já havendo publicado um relatório sobre as escolas superiores de agronomia e veterinária. Vem atuando também na realização do programa de visitas e treinamento, nos Estados Unidos, de líderes rurais, educadores técnicos. O número de bolsas proporcionadas de acordo com esse programa, que data de 1951, chega a 168, beneficiando agrônomos, veterinários, economistas domésticos, agricultores e jovens recém-formados (BRASIL, Ministério da Agricultura. Serviço de Informação Agrícola. Atividades do Ministério da Agricultura em 1954 e 1955. p.173)

Atuando em diversas áreas da produção agrícola, a cooperação bilateral era um instrumento fundamental na consolidação de determinados valores pertinentes à modernização do mundo rural. Destacavam os técnicos do Ministério da Agricultura quanto às atividades do escritório no ano de 1956 que "estudos sobre a cultura da seringueira; assistência técnica à cultura do cacau; trabalhos de economia doméstica e treinamento de técnicos em cooperação com o Ministério da Agricultura foram as principais atividades" do escritório, que ainda realizou “outros trabalhos objetivando o desenvolvimento do nível 
profissional e vem executando um programa de visitas e treinamento, nos Estados Unidos, de líderes rurais, educadores e técnicos brasileiros" e que, quantitativamente, “de 1953 a 1956 foram contempladas 210 pessoas com bolsas de estudos nos Estados Unidos” (BRASIL, Ministério da Agricultura. Serviço de Informação Agrícola. Atividades do Ministério da Agricultura em 1956. p.81-82).

A revista Informação Agrícola, publicada pelo Ministério da Agricultura, em 1958, em comemoração aos 5 anos do acordo e atuação do ETA no Brasil, enfatizou as "Três letras que estão mudando o panorama agrícola do Brasil”. De acordo com o periódico:

Em junho último completou o seu primeiro lustro o Escritório Técnico de Agricultura, órgão executor do acordo firmado dentre os governos do Brasil e dos Estados Unidos para um programa de desenvolvimento da agricultura e recursos naturais do nosso país, comumente conhecido por sua sigla - ETA. Seus objetivos estão sendo plenamente alcançados e disso nos dá testemunho o volume das realizações nesses cinco primeiros anos de existência do acordo, nas mais diversas iniciativas em prol do progresso rural do Brasil. Sua história se resume numa palavra: cooperação (...) A ação do ETA se desenvolve através da assistência técnica e financeira a trabalhos em benefício da agricultura e do agricultor, realizados pelos órgãos do governo e outras entidades públicas ou privadas, principalmente nos setores do treinamento e da extensão rural, através de convênios que recebem o nome de Projeto, seguido de um número de ordem. Até fins de 1957, o ETA assinara, com mais de 70 órgãos diferentes, 46 projetos relativos a trabalhos de educação, pesquisa, conservação de recursos naturais, solo, água, fomento da produção de leite e derivados, cacau, batata-semente, assistência educativa (BRASIL. Ministério da Agricultura. Informação Agrícola. Ano XII. no 153, Julho 1958. p.1)

Sob o postulado da relação entre educação e capital, prestava o Ministério da Agricultura importante papel ao ETA no desenvolvimento do modelo extensionista no Brasil, destacando que:

O Escritório Técnico de Agricultura Brasil-Estados Unidos, órgão inter-governamental com um programa de melhoria agrícola, há perto de seis anos vem operando proveitosamente como instrumento do Ministério da Agricultura. Canalizando a ajuda técnica e financeira prestada através do Ponto IV, seu objetivo é colaborar com departamentos do M.A., assim como de outros órgãos da administração pública, e assistir a programas de educação das massas rurais e à as orientação no sentido de uma agricultura mais racional e produtiva (...) No setor de ensino, cabe menção especial à participação do ETA no convênio, recomendado pelo Ministério da Agricultura, atualmente em execução entre a Universidade Rural do Estado de Minas Gerais e a Universidade norte-americana de Purdue. Visa este programa à modernização do ensino agrícola superior, através de estudos graduados, debates e seminários que deverão beneficiar a cerca de dois mil especialistas e professores universitários e secundários. Do primeiro curso intensivo, dado em princípios deste ano, participaram 107 professores e técnicos, dos quais mais ou menos um terço proveniente dos quadros do Ministério da Agricultura. O ETA presta assistência às especialistas do Ministério e de outros órgãos, empenhados em promover o desenvolvimento das ciências domésticas em níveis médio e superior (...) O cerne dos trabalhos do ETA é a Extensão Rural. É prestado decidido apoio a todas as Associações de Crédito e Assistência Rural que atualmente atendem a perto de 100 mil famílias em 12 Estados da Federação, interessando a uma população de mais de 6 milhões (BRASIL, Ministério da Agricultura. Serviço de Informação Agrícola. Atividades do Ministério da Agricultura em 1960. p.108-110)

A modernização do setor agrícola seria, para os técnicos do Ministério da Agricultura, um projeto inviável sem a transformação do homem mediante a educação, sendo cada vez mais enfatizados os processos educativos informais, como a extensão rural. 
Impulsionado por projetos acríticos e ahistóricos quanto à condição do homem do campo, a educação orientada pelo Ministério da Agricultura buscava cada vez mais integrar educação e modernização do campo, utilizando-se de diversos mecanismos de divulgação de seus projetos.

Integradas ao projeto nacional de extensão rural estavam as chamadas semanas ruralistas, eventos organizados pelos extensionistas e que assumiram importante papel educativo para as populações rurais. Destacavam os quadros do Ministério da Agricultura que:

As "semanas ruralistas" têm constituído um valioso método de difusão das modernas práticas de cultivo e criação, estabelecendo contacto direto de técnicos do Ministério com os produtores (...) Em cada uma destas semanas ruralistas foram dadas aulas, exibido filmes, distribuídas publicações, conduzindo-se cursos rápidos sobre lavoura mecanizada, reflorestamento, combates às doenças e pragas dos animais e das plantas, cooperativismo, higiene rural, criação de gado, principais culturas regionais (...) Cumpre salientar um aspecto das semanas ruralistas: a organização de cursos especiais para as professoras rurais, que, via de regra, ressentem-se da falta de conhecimentos especializados em matéria de agricultura. Com as aulas e demonstrações que lhes são proporcionadas nessas ocasiões, contribui-se de algum modo para a sua qualificação profissional e o melhor desempenho da missão educativa que lhes compete realizar no interior do país (BRASIL. Ministério da Agricultura. Relatórios do Ministério da Agricultura. Atividades do Ministério da Agricultura. 1946-1950. Rio de Janeiro: Serviço de Informação Agrícola, 1951. p.350)

No periódico Informação Agrícola são ressaltadas as ações benéficas das semanas ruralistas, afirmando-se que:

A educação intensiva e extensiva das populações do país deve constituir, na atualidade, um dos mais sérios trabalhos para os governos federais, estaduais e municipais. Existem ainda, no Brasil, aglomerados humanos desenvolvendo atividades as mais primitivas, inteiramente à margem da civilização (...) A obra educacional a realizar-se é verdadeiramente gigantesca e está impondo uma cooperação ampla e perfeita entre os vários órgãos e instituições ligados ao problema, destacando-se, sobretudo, a ação conjugada entre os Ministérios da Educação, Saúde, Agricultura e Trabalho. No setor da educação ruralista propriamente dita, dirigentes e técnicos, de há muito, aconselham medidas não só para a atualização do fomento agropecuário, em termos extensionista, mas também para multiplicar as escolas práticas de agricultura, em suas várias modalidades, e povoar de alunos as escolas superiores de agronomia e veterinária. $\mathrm{O}$ fato é que a agricultura, entre nós, precisa ser profissionalizada, deixando de constituir uma aventura ou uma atividade rotineira, sem acompanhar a evolução extraordinária alcançada pelas técnicas mais modernas. Justamente para chamar a atenção dos nossos homens do interior sobre tais assuntos, lançando idéias novas e proporcionando indicações úteis, é que o Ministério da Agricultura, dentre as múltiplas tarefas ligadas à educação especializada, realiza também as Semanas Ruralistas, nas mais variadas zonas produtoras (...) Enfim, não há como negar a ação benéfica das Semanas Ruralistas, que vem constituindo promissoras sementeiras de idéias sãs, de indicações oportunas e, ainda, de magníficas iniciativas (BRASIL. Ministério da Agricultura. Informação Agrícola. Ano XII. no 152, Junho 1958. p.11)

Tendo em vista as exposições do Ministério da Agricultura sobre educação e cooperação técnica, ainda mais pode ser destacado o papel do projeto extensionista para o mundo rural, atuando, através de uma proposta modernizante, como verdadeiro aparato ideológico, assumindo a ABCAR, um de seus órgãos difusores, importante papel como aparelhos de ideologia. Vejamos.

Sob a tutela da extensão rural, o M.A implantava métodos pertinentes à assistência aos produtores rurais no seu trabalho, direcionando-o para o melhoramento da produção e à disseminação de conhecimentos referentes a diferentes métodos de produção. Esse processo era decorrente tanto pela 
aquisição e uso de máquinas agrícolas quanto pela melhoraria, por meio de um trabalho educativo, do nível de vida das populações rurais (BRASIL. Ministério da Agricultura. Informação Agrícola. Ano VIII. no 117, Julho 1955. p.8).

O discurso modernizante da extensão rural atuava como elemento de uma ruptura histórica, deixando para trás o atraso e trazendo para o campo a idéia de civilização. Como expôs um extensionista em 1957, “Aquele que se propõe a resolver os problemas da agricultura brasileira sem o concurso da Extensão Agrícola, é como o homem que com as mãos desarmadas tenta mover uma rocha de 10 toneladas - ou é louco ou desconhece o seu peso” (BRASIL. Ministério da Agricultura. Informação Agrícola. Ano I. n 3, jul 1957 CAPA).

$\mathrm{Na}$ matéria "Levando aos que moram no campo os benefícios da civilização", o periódico Informação Agrícola destacou um treinamento orientado pelo ETA e pela ABCAR na cidade de Divinópolis, através da realização de cursos destinados a "levar aos que vivem no campo - homens e mulheres - novos métodos de trabalho, superando a rotina antiquada em que muitos ainda vivem, deixando de usufruir as vantagens incontestáveis que o progresso traz até as cidades" (BRASIL. Ministério da Agricultura. Informação Agrícola. Ano XII. no 152, Junho 1958 .p.4)

Ao completar seu primeiro decênio de existência, os técnicos da ABCAR referendaram sua proposta de modernizar o campo brasileiro pela extensão rural e seus processos educativos, destacando que a ABCAR “expandiu-se a ponto de suas filiadas já estarem prestando orientação técnica e educativa aos agricultores e às suas famílias em 831 municípios, que representam mais da quarta parte dos existentes nos 17 Estados onde funcionam os serviços de Extensão Rural" (BRASIL. Ministério da Agricultura. Informação Agrícola. Ano I. no 11, ago 1966. p.27), sendo a chave, tanto para o crescimento quantitativo quanto para as mudanças qualitativas de tal empreendimento:

O entrosamento do Sistema de Extensão com as atividades do Ministério da Agricultura e de outros órgãos federais e estaduais, estabelecimentos de crédito, entidades privadas e agências internacionais, todos por igual interessados em promover o desenvolvimento rural, tem sido a razão principal do seu êxito. Assim, na execução dos trabalhos de Extensão, a ABCAR realiza um movimento amplo de harmonização de instituições, conjugação de recursos técnicos e financeiros, e articulação de programas visando a racionalizar as práticas vigentes de exploração agropecuária, aumentar a produtividade do setor e melhorar o nível de vida das famílias rurais (BRASIL. Ministério da Agricultura. Informação Agrícola. Ano I. no 11, ago 1966. p.27)

A expansão da extensão agrícola no Brasil na década de 1960, apresentada na tabela 1, mais que um dado quantitativo e a partir das discussões apresentadas, remete à instrumentalidade da ABCAR como aparelho de ideologia, instituído em ocultar aspectos estruturais da desigualdade nacional.

Tabela 1 - Escritórios vinculados à Associação Brasileira de Crédito e Assistência Rural (ABCAR) em funcionamento no Brasil, ano de criação e municípios atendidos até 30 de junho de 1960

\begin{tabular}{|c|c|c|c|c|}
\hline \multirow{2}{*}{ FILIADAS } & $\begin{array}{c}\text { INÍCIO DAS } \\
\text { ATIVIDADES }\end{array}$ & \multicolumn{2}{|c|}{$\begin{array}{c}\text { ESCRITÓRIOS EM FUNCIONAMENTO } \\
\text { Locais }\end{array}$} & $\begin{array}{c}\text { MUNICÍPIOS } \\
\text { ATINGIDOS }\end{array}$ \\
\hline ACAR & 1949 & 9 & 61 & 18 \\
\hline ANCAR-CE & 1954 & 2 & 10 & 20 \\
\hline ANCAR-RN & 1955 & 1 & 10 & 25 \\
\hline ANCAR-PB & 1955 & 2 & 8 & 18 \\
\hline
\end{tabular}




\begin{tabular}{|c|c|c|c|c|}
\hline ANCAR-PE & 1954 & 1 & 9 & 9 \\
\hline ANCAR-BA & 1954 & 2 & 8 & 25 \\
\hline ASCAR & 1956 & 5 & 21 & 25 \\
\hline ACARESC & 1956 & 3 & 14 & 14 \\
\hline ACARPA & 1956 & - & 6 & 6 \\
\hline ACARES & 1957 & - & 6 & 11 \\
\hline ACAR-RJ & 1958 & - & 189 & 275 \\
\hline ACAR-Goiás & 1959 & 26 & 11 & 28 \\
\hline Total & & & & 14 \\
\hline
\end{tabular}

FONTE: BRASIL. Ministério da Agricultura. Relatório do Ministério da Agricultura. 1961.p.40

Exposta a forma de operacionalização da ABCAR, cabe agora abordar, partindo das reflexões de Poulantzas, como a ideologia se manifesta nesse contexto.

Para Poulantzas, a ideologia, enquanto ideologia dominante, ultrapassa o aspecto repressivo ligado às funções típicas do Estado, do qual detém o monopólio do uso legítimo da força e da repressão física organizada (Exército, Legislativo, Judiciário), utilizando-se de agentes e instituições (Igreja, partidos políticos, sindicatos, sistema escolar, meios de comunicação, etc.) responsáveis pela inculcação ideológica, constituindo-se em um poder essencial das classes numa formação social. Para Poulantzas, a ideologia não possui configuração "neutra", pois somente existem ideologias de classe, que consistem em relações de poder absolutamente essenciais numa formação social. (POULANTZAS, 1972. p.87-89)

Como afirma o autor:

O Estado, que é um Estado de classe, não se define somente pela detenção da "força" física repressiva, mas principalmente pelo seu papel social e político. O Estado de classe é a instância central cujo papel consiste na manutenção da unidade e da coesão de uma formação social, na manutenção das condições de produção e, assim, na reprodução das condições sociais da produção: é, num sistema de luta de classes, a garantia da dominação política de classe. Ora, é esse, muito exatamente, o papel que os aparelhos ideológicos desempenham: nomeadamente, a ideologia dominante "cimenta" a formação social. (POULANTZAS, 1972. p.89)

Como exposto, o sistema de extensão rural no Brasil, ao elencar os problemas do espaço agrário nacional como decorrentes de baixos níveis de educação e da ausência de técnicas modernas de cultivo, ocultou problemas historicamente presentes na formação social brasileira, como a concentração fundiária, tornando inclusive ilegítimas as demandas sociais por redistribuição de terras.

Por fim, destaca-se a reflexão de Poulantzas sobre a natureza jurídica das instituições sociais, cuja definição entre publicas e privadas não afasta a configuração de aparelho de Estado. Embora o periódico Informação Agrícola definisse a Associação Brasileira de Crédito e Assistência Rural como uma “instituição de direito privado, sem fins lucrativos”, da qual participam o Ministério da Agricultura, o Ministério da Educação e Cultura, o Serviço Social Rural, a Confederação Rural Brasileira, o Banco do Brasil S/A, a American International Association (AIA) e o Escritório Técnico de Agricultura (ETA) e destinada ao "apoio e coordenação dos serviços de Extensão Rural e Crédito Supervisionado que executam, nos Estados, programas técnico-educativos para elevação dos níveis de vida das populações do campo" (BRASIL. Ministério da Agricultura. Informação Agrícola. Ano IV. no 33, mar 1960), deve-se entendê-la, dada suas funções de cimentar a ideologia dominante, como um aparelho ideológico do Estado. 
Nesse sentido, alerta-nos Poulantzas que:

O facto de os aparelhos ideológicos de Estado terem, muitas vezes, um caráter "privado", isto é, não oficialmente reconhecido como aparelhos de Estado, não deve surpreender. Com efeito, a distinção entre "privado" e "público" é uma distinção puramente jurídica. Contra uma certa concepção que indica, como linha de demarcação entre "sociedade civil" e "Estado", isto é, como lugar de constituição do Estado, uma distinção "pré-jurídica", quase ontológica, entre privado e público, é preciso ver bem que é, de facto, o direito - quer dizer, num sentido, o próprio Estado - que estabelece esta distinção: ela tem apenas um sentido jurídico. Esta distinção "privado-público" nada muda, pois, em nada, o fundo da questão dos aparelhos ideológicos do Estado (POULANTZAS, 1972. p.92-93)

\section{Considerações finais}

Pensar e analisar o papel da ideologia nas sociedades contemporâneas é um aspecto fundamental para compreender a dinâmica das relações de dominação, partindo do pressuposto que o poder de uma classe sobre as demais não é exercido apenas mediante a coerção e a influência sobre os aparelhos repressivos do Estado. Cabe ao pesquisador avançar sobre a suposta neutralidade da ideologia (assim difundida pelos grupos dominantes), de forma a compreender sua dimensão e nuances. A partir dessa reflexão, podemos analisar e construir um conhecimento crítico acerca da instrumentalidade dos diversos aparelhos do Estado.

\section{Referências}

BRASIL. Ministério da Agricultura. Relatórios do Ministério da Agricultura. Atividades do Ministério da Agricultura. 1946-1950. Rio de Janeiro: Serviço de Informação Agrícola, 1951

BRASIL. Ministério da Agricultura. Serviço de Informação Agrícola. Atividades do Ministério da Agricultura em 1954 e 1955.

BRASIL. Ministério da Agricultura. Informação Agrícola. Ano VIII. no 117, Julho 1955

BRASIL. Ministério da Agricultura. Serviço de Informação Agrícola. Atividades do Ministério da Agricultura em 1956

BRASIL. Ministério da Agricultura. Informação Agrícola. Ano I. nº 3, jul 1957

BRASIL. Ministério da Agricultura. Informação Agrícola. Ano XII. no 152, Junho 1958

BRASIL. Ministério da Agricultura. Informação Agrícola. Ano XII. no 153, Julho 1958

BRASIL. Ministério da Agricultura. Serviço de Informação Agrícola. Atividades do Ministério da Agricultura em 1960

BRASIL. Ministério da Agricultura. Informação Agrícola. Ano IV. no 33, mar 1960

BRASIL. Ministério da Agricultura. Relatório do Ministério da Agricultura. 1961

BRASIL. Ministério da Agricultura. Informação Agrícola. Ano I. no 11, ago 1966.

COLBY, Gerard; DENNETT, Charlotte. Seja feita a vossa vontade: a conquista da Amazônia: Nelson Rockefeller e o evangelismo na idade do petróleo. Tradução de Jamari França. Rio de Janeiro: Record. 1998.

ENGELS, Friedrich. A origem da familia, da propriedade privada e do Estado. Civilização Brasileira, $9^{\circ}$ Ed: Rio de Janeiro, 1984.

MOREIRA, Vânia Maria Losada. Os anos JK: industrialização e modelo oligárquico de desenvolvimento rural. In: FERREIRA, Jorge e DELGADO, Lucilia de Almeida Neves (Orgs.). O Brasil republicano. O tempo 
da experiência democrática. Da democratização de 1945 ao golpe civil-militar de 1964. Livro 3. Rio de Janeiro: Civilização Brasileira, 2003.

POULANTZAS, Nicos. Fascismo e ditadura: a III Internacional face ao fascismo. II volume. Portucalense Editora: Porto, Portugal, 1972.

POULANTZAS, Nicos. Poder político e classes sociais. São Paulo: Martins Fontes, 1977.

UNITED STATES OF AMERICA. Agreement for a cooperative program of agriculture between the government of the United States of Brazil and the government of the United States of America (26/03/1953). Washington: TIAS, 1953.

\section{Notas:}

${ }^{1}$ Doutorando do Programa de Pós-graduação em História da Universidade Federal Rural do Rio de Janeiro. Mestre em História pelo Programa de Pós-graduação em História da Universidade Federal Rural do Rio de Janeiro. Membro do Grupo de Estudos sobre o Agro Contemporâneo (GEAC), onde atua nas áreas de Estado, atores sociais e políticas de desenvolvimento para o meio rural no Brasil e Organização, ação e representação política do patronato rural e agroindustrial no Brasil. Orcid: https://orcid.org/0000-0003-4781-1962 Email: luckasoab@yahoo.com.br

2 A primeira missão extensionista no Brasil foi implementada a partir do acordo entre a American International Association for Economic and Social Development (AIA) e o governo de Minas Gerais. Destacam Colby e Dannett que "Em 1948, Nelson e Milton Campos, governador de Minas Gerais, assinaram um acordo para estabelecer uma agência de crédito agrícola, a ACAR (Associação de Crédito e Assistência Rural). A AIA de Rockefeller administraria a agência, que controlava o acesso a empréstimos a $8 \%$ de um banco estatal. Até mesmo os gastos dos produtores eram controlados por equipes técnicas de uma agência local, que tinham autoridade sobre as contas dos fazendeiros. Para onde ia parte desse dinheiro era previsível: o agroempresário Rockefeller" (COLBY E DANNET'T, 1998. p.251).

Recebido em: 05.22.2019

Aprovado em: 13.05 .2020 